\title{
Effects of posture in hiatus hernia as studied by oesophageal $\mathrm{pH}$ measurement
}

\author{
K. S. HABIBULLA, J. F. AMMANN, and J. LEIGH COLLIS \\ Oesophageal Laboratory, Queen Elizabeth Hospital, Birmingham 15
}

\begin{abstract}
The use of postural restriction in the treatment of patients with hiatus hernia has been analysed using continuous oesophageal $\mathrm{pH}$ measurements. It appears that it is not effective in the prevention of reflux of acid. The percentage of the time during which oesophageal $\mathrm{pH}$ remains below 5 is not significantly different when comparison is made during periods of sitting and lying. The frequency of reflux episodes is actually greater in the sitting position, but the duration of each reflux episode is significantly shorter than when lying. It is suggested that the undoubted symptomatic benefit derived by hiatus hernia patients from adopting the sitting position is explained by improved clearance of regurgitated acid.
\end{abstract}

This is a study into the effect of postural restriction on gastro-oesophageal reflux and into the rationale for its use in treatment.

Fluoroscopy is a readily available and easy method for the examination of gastro-oesophageal reflux but the method lacks accuracy and does not lend itself easily to comparison between cases. In view of this, measurement using an indwelling $\mathrm{pH}$ electrode was chosen for this investigation (Tuttle and Grossman, 1958; Piccone, Gutelius, and McCorriston, 1965 ; Kantrowitz, Corson, Fleischli, and Skinner, 1969). A prolonged oesophageal $\mathrm{pH}$ recording, as suggested by Spencer (1969), was favoured as this establishes the pattern of gastro-oesophageal reflux in an individual patient.

\section{METHOD}

A dual pH glass electrode is used (Cambridge Instrument Company). In this a small glass electrode is connected to a $\mathrm{pH}$ meter by a co-axial wire. The reference half-cell is a salt-bridge $(3.5 \mathrm{M}$ potassium chloride solution) in the other lumen of the dual electrode connexion. A sintered glass plug near the distal end of the electrode retains the potassium chloride in the lumen of the tube though allowing diffusion at a rate of $7 \mu \mathrm{l} / \mathrm{hr}$, thus establishing a closed electrical circuit. The output from the electrode is measured using a modified ammeter (Pye Unicam, model $292 \mathrm{pH}$ meter). Permanent records are obtained with a pen-writing galvanometric recorder ('Inkwell' model). The response-time sensitivity 1Requests for reprints to: Professor J. Leigh Collis, Queen
Elizabeth Hospital, Edgbaston, Birmingham 15 of this apparatus is $0.5 \mathrm{~s}$, and a paper speed of $1 \mathrm{in} / \mathrm{hr}$ is used, as this speed is practical while still allowing satisfactory analysis of the tracing.

The $\mathrm{pH}$ glass electrode was passed transnasally in the evening with little difficulty or discomfort to the patient and was positioned $5 \mathrm{~cm}$ above the cardiac sphincter. The exact level of this sphincter was previously determined using manometric studies (Woodward, 1970) and simultaneous recordings of transmucosal potential change (Helm, Schlegel, Code, and Summerskill, 1965). The electrode was firmly anchored to the cheek with adhesive tape (Fig. 1).

A standard meal of two scrambled eggs, two slices of bread, and a cup of Bovril was given to fill and stimulate the stomach. After this meal oesophageal $\mathrm{pH}$ was recorded for five hours with the patient propped up in bed and supported by a bedwedge. Care was taken to ensure that this position

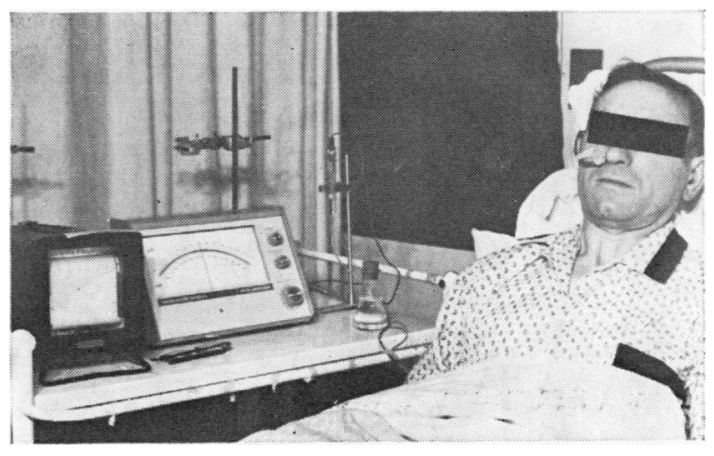

FIG. 1. The electrode system is shown connected to the patient. The pH meter stands in the middle of the table. 
was maintained. A similar meal was then given and the recording continued for a further five hours with the patient lying flat. In some tests the order was reversed, the lying period preceding the sitting period. The patient himself was instructed to note the times of meals, changes of posture, and incidence of symptoms during the test. This information was correlated with the oesophageal $\mathrm{pH}$ tracing. The electrode was tested before and after recording for reliability, sensitivity, and drift. No alteration in sensitivity or significant drift was found in any case.

PATIENTS Thirty-five tests were performed on patients divided into three groups.

Group I consisted of 20 hiatus hernia patients with symptomatic and radiological reflux.

Group II consisted of 10 patients with hiatus hernia and peptic stricture of the oesophagus, prior to dilatation being performed.

Group III consisted of five volunteers who had no gastrointestinal symptoms. These were included in this study to establish the pattern of reflux during a similar test period.

ASSESSMENT OF SYMPTOMS The severity of each patient's reflux symptoms was 'scored' using the following method. A score of 0,1 , or 2 was given to increasing degrees of severity of $(a)$ heartburn after food, (b) heartburn with postural indiscretion, (c) acid regurgitation after food, and (d) acid regurgitation with postural indiscretion. The total score therefore ranges between 0 and 8 . Dysphagia was entered separately whenever it was present.

OESOPHAGITIS This was assessed visually at oesophagoscopy as described previously (Ward, Wright, and Collis, 1970) and was graded as follows:

$\mathrm{O}-$ no oesophagitis
A-minimal oesophagitis

B-moderate oesophagitis, where mucosa was red and bled easily

C-severe oesophagitis including stricture.

ANALYSIS OF $\mathrm{pH}$ TRACINGS The tracings produced by the method described were analysed in three ways:

1. Total number of reflux episodes below pH 5 This was a straightforward calculation made by counting the number of peaks on the recording providing these peaks reached $\mathrm{pH} 5$.

2. Percentage of time with increased oesophageal ते acidity The percentage of the time was preferred of to the actual time as small variations in the total os duration of the test might otherwise have led to $\infty$ inaccuracy. The tests did in fact vary in length from $4 \frac{1}{2}$ to $5 \frac{1}{2}$ hours. This calculation was therefore made from two figures. The first was the actual total time of the test and the other was the sum of the lengths of all the individual reflux episodes. The result was expressed as a percentage from the following formula:

Total time with increased oesophageal acidity

Total time of period of test $\times 100$.

This calculation was made at various $\mathrm{pH}$ levels from 5 to 2 but only the figures from the findings at $\mathrm{pH} 5$ were used for the subsequent analysis.

3. Mean duration of each reflux episode With these tests it became apparent that the pattern of the clinical response and the number of reflux episodes was not similar. Some other factor seemed important. The parameter chosen for further analysis was the mean duration (length) of each reflux episode. This distinction allows investigation into whether short episodes of reflux can be tolerated however many are present.

\section{QEH 810033}

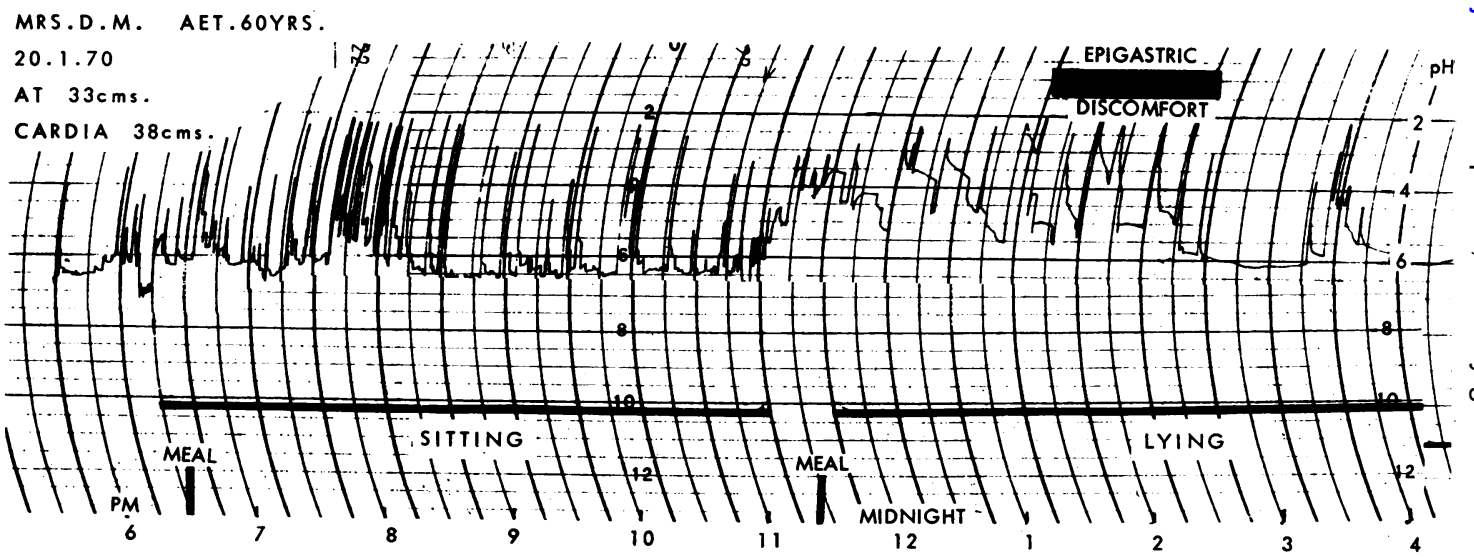

FIG. 2. A typical recording of reflux pattern from an uncomplicated hiatus hernia patient. Note the short and frequent reflux episodes in the sitting position and the longer and fewer episodes while lying. Note also the association of heartburn with the long reflux episodes. 
As opposed to this it seemed desirable to find out whether longer episodes did more harm even though they may have been in small numbers. The figure was obtained from the following formula:

Total time under pH 5 for each period

Number of reflux episodes during same time.

\section{RESULTS}

The typical reflux pattern from one of the patients is shown in Figure 2. In 21 patients the sitting up period preceded the lying down period. In nine patients the order was reversed. As the results were unaffected by changing the order they will be considered together.

1. TOTAL NUMBER OF REFLUX EPISODES BELOW PH 5 (Table I)

Group I When sitting up the mean number of reflux episodes per patient was $17 \cdot 3$ whereas when lying down the mean number of reflux episodes was significantly smaller at 9.4. In 17 patients there were more reflux episodes when sitting than when lying and only in three were there more reflux episodes in the lying position than when sitting.

\section{T A B LE I}

MEAN NUMBER OF REFLUX EPISODES IN EITHER POSITION

\begin{tabular}{|c|c|c|c|c|}
\hline \multirow{2}{*}{ Group } & \multicolumn{2}{|c|}{ Position } & \multirow{2}{*}{ Significance } & \multirow{2}{*}{ Remarks } \\
\hline & Sitting & Lying & & \\
\hline $\bar{I}$ & $17 \cdot 3( \pm 4 \cdot 7)$ & $9 \cdot 4( \pm 2 \cdot 1)$ & $P<0.001$ & $\begin{array}{r}17 \text { sitting }>\text { lying } \\
3 \text { lying }>\text { sitting }\end{array}$ \\
\hline II & $15.4( \pm 1 \cdot 7)$ & $8 \cdot 2( \pm 1 \cdot 2)$ & $\begin{array}{c}\text { Not } \\
\text { significant }\end{array}$ & $\begin{array}{l}7 \text { sitting }>\text { lying } \\
2 \text { sitting }=1 \text { lying } \\
1 \text { lying }>\text { sitting }\end{array}$ \\
\hline
\end{tabular}

Group I consists of those patients who have a simple hiatus hernia with reflux. In this group more reflux episodes occur in the sitting position. The same could not be demonstrated in the series (group II) but testing is made awkward because of the barrier to reflux produced by the stricture itself.

Group II When sitting up the mean number of reflux episodes per patient was 15.4 whereas lying down it was $8 \cdot 2$, but this difference was not statistically significant. However, again there were more reflux episodes in seven patients when sitting; two had equal numbers when sitting or lying but only one had more reflux episodes when lying.

2. PERCENTAge OF TIME WITH INCREASEd OesoPHAGEAL ACIDITY

Group I (Table II) Considering an oesophageal $\mathrm{pH}$ of 5 or below, the mean percentages when sitting and lying were $26.3 \%$ and $33 \%$ respectively. This difference was not statistically significant. The same relationship was found when using the time below $\mathrm{pH} 4,3$, and 2 .

\section{T A B L E I I}

MEAN PERCENTAGE TIME WITH INCREASED OESOPHAGEAL ACIDITY AT DECREASING $p H$ LEVELS IN EITHER POSITION IN GROUP I PATIENTS

\begin{tabular}{c|c|c|c}
\hline \multirow{2}{*}{ pH } & \multicolumn{2}{|c|}{ Position } & \\
\cline { 2 - 3 } & Sitting (\%) & Lying (\%) & \\
\hline$<5$ & 26.3 & 33 & Not significant \\
$<4$ & 15.9 & 16.7 & Not significant \\
$<3$ & 5.2 & 5.8 & Not significant \\
$<2$ & 1.2 & 1.4 & Not significant \\
\hline
\end{tabular}

These figures demonstrate that the $\mathrm{pH}$ levels are approximately the same in the sitting and lying positions. The expected protection from adopting the sitting position did not occur.

Group II (Table III) Considering an oesophageal $\mathrm{pH}$ of 5 or below, the mean percentages when sitting and lying were $23 \%$ and $34 \%$ respectively. This shows a trend similar to that of group I, but again the difference is not statistically significant.

\section{T A B L E I I I}

MEAN PERCENTAGE TIME WITH INCREASED OESOPHAGEAL ACIDITY AT DECREASING pH LEVELS IN EITHER POSITION IN GROUP II PATIENTS

\begin{tabular}{c|c|c|c}
\hline \multirow{2}{*}{ pH } & \multicolumn{2}{|c|}{ Position } & Significance \\
\cline { 2 - 3 } & Sitting (\%) & Lying (\%) & \\
\hline$<5$ & 23.0 & 34 & Not significant \\
$<4$ & 12.0 & 19.2 & Not significant \\
$<3$ & 3.3 & 4.8 & Not significant \\
$<2$ & 0.4 & 0.6 & Not significant \\
\hline
\end{tabular}

As in Table II a lower pH level might have been expected in the lying position. The figures show no statistical difference between the two positions.

3. MEAN DURATION OF EACH REFLUX EPISODE (Table IV)

Group I Calculations were made at pH 5 only. The mean duration of each reflux episode was, in the sitting position, only 3.4 minutes, whereas in the lying position it was 11.8 minutes. This was statistically highly significant $(\mathrm{P}<0.001)$.

Group II The mean duration of each reflux episode was 4.0 minutes when sitting and 10.6 
T A B L E I V

MEAN DURATION OF EACH REFLUX EPISODE IN EITHER POSITION IN MINUTES

\begin{tabular}{c|c|c|c}
\hline \multirow{2}{*}{ Group } & \multicolumn{2}{|c|}{ Position } & Significance \\
\cline { 2 - 4 } & Sitting & Lying & \\
\hline I & $3.4( \pm 0.7)$ & $11.8( \pm 1.8)$ & $P<0.001$ \\
II & $4.0( \pm 0.8)$ & $10.6( \pm 1.4)$ & $P<0.001$ \\
\hline
\end{tabular}

Note the significant difference in mean duration of each reflux episode between lying and sitting in both groups. In the lying position the duration of each reflux episode is $3 \frac{1}{2}$ times longer in uncomplicated duration of each reflux episode is $3 \frac{1}{2}$ times longer in uncomplicated
hiatus hernia patients (group I) and $2 \frac{1}{2}$ times longer in stricture patients (group II).

minutes when lying. This again is a highly significant difference $(\mathrm{P}<0.001)$.

Group III (Controls-5 normal volunteers) There were no reflux episodes in either the sitting or lying position. Figure 3 shows a typical tracing from a volunteer. In all controls the $\mathrm{pH}$ of the oesophagus remained between 7 and 6.5 or between $6 \cdot 5$ and $6 \cdot 0$.

RELATION OF SYMPTOM SCORE AND OESOPHAGITIS In groups I and II the total number of refiux episodes, the percentage of time with increased oesophageal acidity under $\mathrm{pH} 5$, and the mean duration of each reflux episode were considered against the symptom score obtained from the history and the oesophagoscopy findings. No correlation was shown between these factors (Fig. 4a and b).

SYMPTOMS DURING TEST Only nine patients in groups I and II had symptoms and, of these, only eight complained of heartburn during the period of testing. The incidence of this symptom was correlated with the $\mathrm{pH}$ tracing in respect of any incidence of oesophageal acidity during the episode of heartburn.

A positive correlation was found in one patien 5 when both sitting and lying, in five patients whenlying, and in only one patient when sitting. One्ల్ patient had heartburn when lying which was not correlated with increased oesophageal acidity.

A further patient complained of retrosternati pain, not definitely heartburn in character, which? was continuous throughout the test in both posiog tions. This pain showed good correlation with increased acidity when sitting but not when? lying.

Two patients had to sit up during the lying down period because of severe heartburn; the pH rose immediately with symptomatic relief. A tracing from one such patient is shown in Fig. 5.

\section{DISCUSSION}

Our findings in the group of uncomplicated symptomatic hiatus hernia patients and in the stricture group are surprising. Radiologica芩 studies had shown that these patients refluxed more readily when lying flat than when standing In the lying position barium is presented to the cardia and, in the absence of an effective barriee here, reflux occurs more readily. It might be supposed that acid gastric contents behave in similar manner. These studies are at variance with this supposition. It must be noted that in these oesophageal pH tests sitting and lying posis

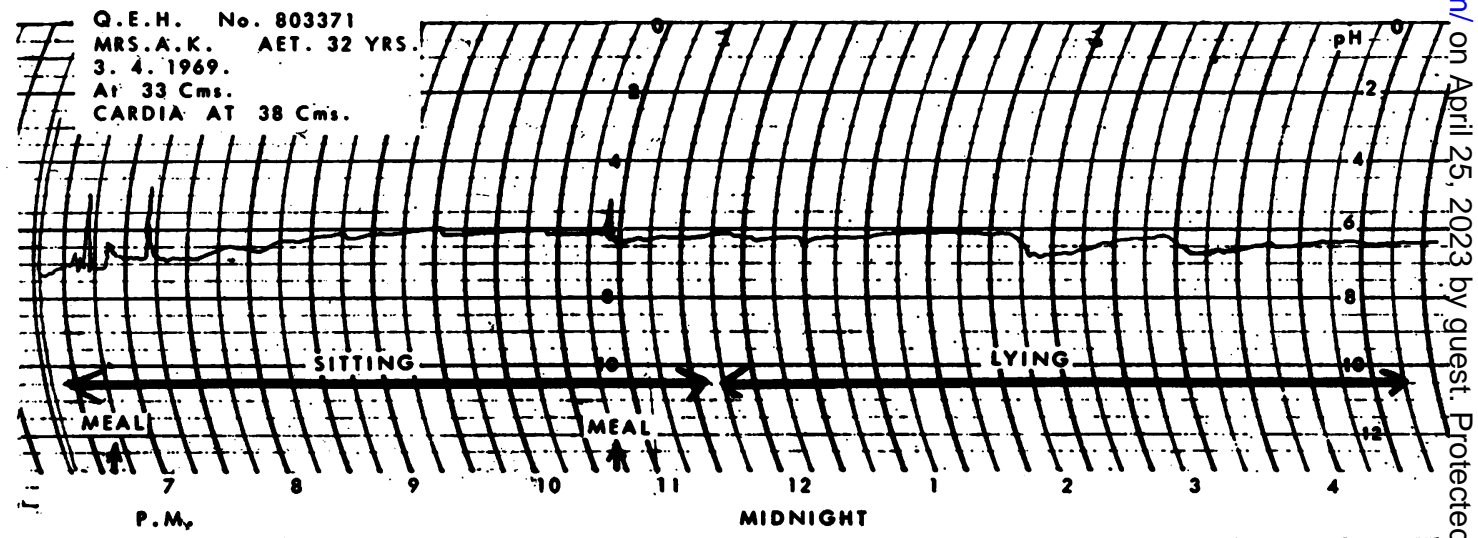

IFIG. 3. A tracing from a normal individual. Note that the basal oesophageal pH remains at a nearly neutral pH. This patient had only three reflux episodes which is in marked contrast with the pattern of reflux shown in Figure 2. 

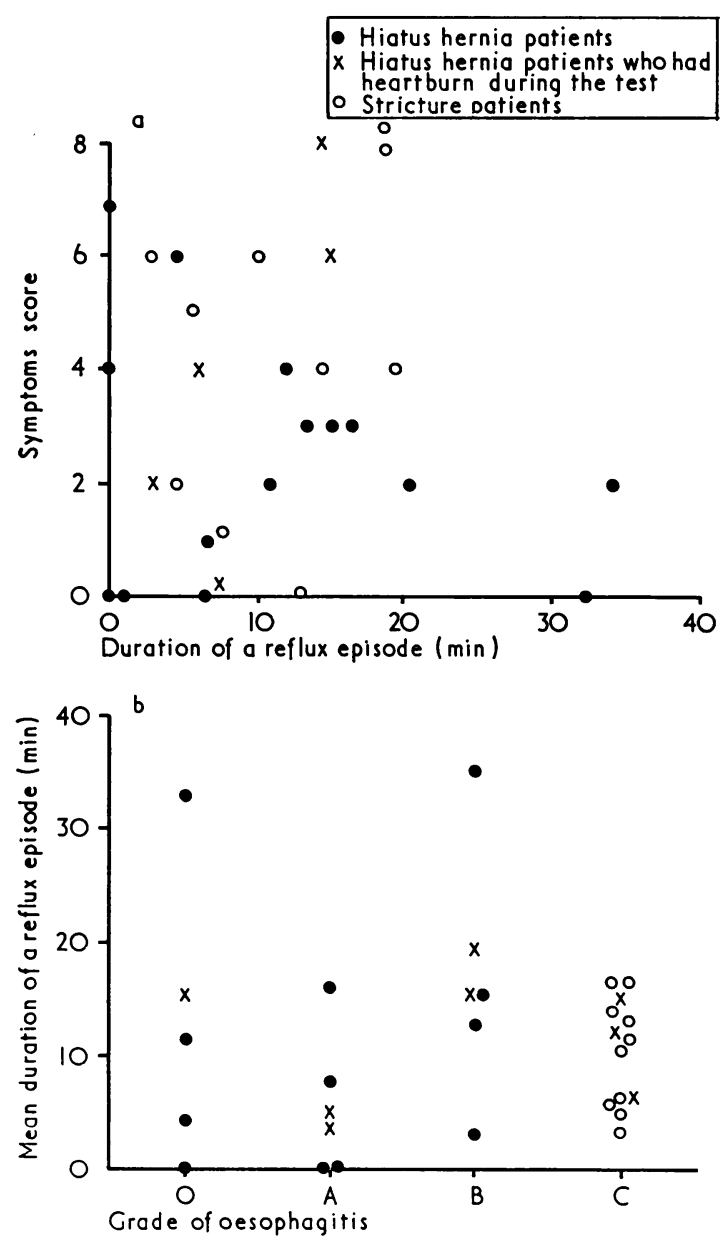

FIG. 4(a). A scattergram showing relationship between mean duration of a reflux episode under $\mathrm{pH} 5$ and severity of symptoms using the method of scoring as described in the text. Note the wide scatter of patients who had actual heartburn during the test. There was no correlation between severity of symptoms and duration of a reflux episode.

FIG. 4(b). Shows relationship between grade of oesophagitis and mean duration of a reflux episode. Note there is no correlation between mean duration of a reflux episode and severity of oesophagitis. Note also those patients who had heartburn during the test are uniformly present in every grade of oesophagitis.

tions are compared and not standing and lying, as is the case in barium studies.

Marchand (1955) and Nagler and Spiro (1961) showed that increasing the intra-abdominal pressure increased the reflux. It might be postulated that there is an increase of intra-abdominal pressure when sitting, but Fyke, Code and Schlegel
(1956) showed that the intragastric pressure is less when sitting than when lying flat. They further demonstrated that the band of high pressure at the cardia is narrowest and its pressure lowest when subjects are sitting. Pattrick (1970) believes that there is a degree of physiological incompetence of the cardia in the upright position and even demonstrated frequent acid reflux into the oesophagus when standing.

Patients with hiatus hernia and strictures were separated from those with uncomplicated hiatus hernia in order to see whether patients in each group behaved differently. The stricture group (group II) of our patients had similar findings to those of patients with hiatus hernia but without stricture (group I).

Although the differences between the two groups are not significant, it is worth noting that the mean number of reflux episodes in the stricture group is not significantly greater in the sitting position whereas it is significant in uncomplicated hiatus hernia patients. This is because of the barrier to reflux produced by the stricture itself. This may also explain why the ratio for the mean duration of each reflux episode between sitting and lying is less in the stricture group II than in the uncomplicated hernia group $\mathbf{I}$.

So far our results show that asking a patient to sleep propped up does not significantly reduce the total period of increased oesophageal acidity and that the number of reflux episodes is actually increased. This is in accord with the findings of Woodward (1970) who demonstrated no relation between the time under $\mathrm{pH} 4$ and the symptoms of reflux present.

In spite of this there is the inescapable fact that patients regularly find that postural restriction and, in particular, sleeping propped up helps them greatly. In the present investigation only four patients-all in the uncomplicated hiatus hernia group-did not benefit from postural restriction clinically, and also those patients who had actual heartburn during the testing support the value of postural restriction (Figs 4 and 6). Posture is therefore important but what is being questioned is the way in which it operates.

The analysis of our results shows that though the total period of increased oesophageal acidity may not be relevant, the mean duration of each reflux episode is significantly shorter when sitting than when lying. This is irrespective of the total number of reflux episodes in any particular position. The shorter reflux episodes suggest better clearance of the irritant regurgitated acid from 




FIG. 5. A recording from a patient with a minimal degree of stricture. Note the good correlation between the heartburn and increased oesophageal acidity. Note also the reduction of oesophageal acidity and relief of heartburn with change of $Z$ posture.
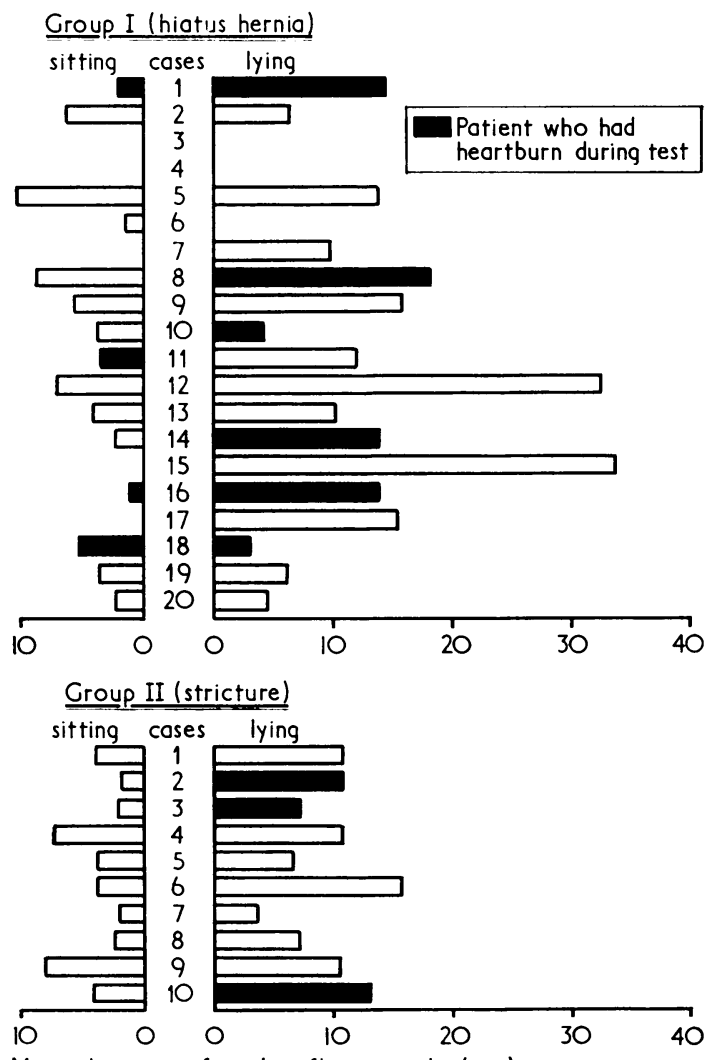

Mean duration of each reflux episode (min)

FIG. 6. Details of patients who had heartburn during oesophageal monitoring. Note the definite increase in the duration of reflux episodes while patients are lying down. It is also clear that patients have heartburn more while lying (right-hand blocks) than when sitting (left-hand blocks).

the oesophagus in the upright position. The importance of oesophageal clearance has been demonstrated by many workers (Olsen and $\vec{\varphi}$ Schlegel, 1965 ; Booth, Kemmerer, and Skinner, .1968 ; Cocco and Brantigan, 1969 ; Skinner and Booth, 1970).

It seems therefore that although reflux is not prevented in the sitting position, oesophageal clearance is improved. It may further be assumed $\stackrel{\varnothing}{\perp}$ that the oesophagus can withstand the shorter $\stackrel{2}{\Rightarrow}$ reflux episodes and that it is the absence of pro- $\frac{0}{3}$ longed reflux episodes in the sitting position that provides the patient with relief. It seems worthy of comment that Aylwin's (1953) statement concerning the dangers of nocturnal reflux should be rephrased in the light of the above findings.

We are grateful to Mr. A. Jowett for his helpful criticism; to Miss P. Cole of the Surgical Research Wing for the preparation of graphs ; to Mr. T. Dee, そ our chief clinical photographer; to Mr. D. H. Barer 옥 for statistical help; and to our secretary Miss M. T. Isherwood.

This research was financed from the endowment fund of the United Birmingham Hospitals. ON

\section{REFERENCES}

Aylwin, J. A. (1953). The physiological basis of reflux oesophagitis in sliding hiatal diaphragmatic hernia. Thorax, 8, 38 .

Booth, D. J., Kemmerer, W. T., and Skinner, D. B. (1968). Acid clearing from the distal esophagus. Arch. Surg., 96, प 731.

Cocco, A. E., and Brantigan, O. C. (1969). Esophagitis: Diagnosis and surgical treatment. Ann. Surg., 169, 857.

Fyke, F. E. Jr., Code, C. F., and Schlegel, J. F. (1956). The $\varrho$ gastroesophageal sphincter in healthy human beings. Gastroenterologia (Basel), 86, 135. 
Helm, W. J., Schlegel, J. F., Code, C. F., and Summerskill, W. H. J. (1965). Identification of the gastroesophageal mucosal junction by transmucosal potential in healthy subjects and patients with hiatal hernia. Gastroenterology, 48, 25.

Kantrowitz, P. A., Corson, J. G., Fleischli, D., and Skinner, D. B. (1969). Measurement of gastroesophageal reflux. Gastroenterology, 56, 666.

Marchand, P. (1955). The gastro-oesophageal 'sphincter' and the mechanism of regurgitation. Brit.J. Surg., 42, 504.

Nagler, R., and Spiro, H. M. (1961). Heartburn in late pregnancy. Manometric studies of esophageal motor function. J. clin. Invest., 40, 954.

Olsen, A. M., and Schlegel, J. F. (1965). Motility disturbances caused by esophagitis. J. thorac. cardiovasc. Surg., 50, 607.

Pattrick, F. G. (1970). Investigation of gastroesophageal reflux in various positions with a two-lumen $p \mathrm{H}$ electrode. Gut, 11, 659.
Piccone, V. A., Gutelius, J. R., and McCorriston, J. R. (1965). A multiphase esophageal $p \mathrm{H}$ test for gastroesophageal reflux. Surgery, 57, 638.

Skinner, D. B., and Booth, D. J. (1970). Assessment of distal esophageal function in patients with hiatal hernia and/or gastroesophageal reflux. Ann. Surg., 172, 627.

Spencer, J. (1969). Prolonged $p \mathrm{H}$ recording in the study of gastro-oesophageal reflux. Brit. J. Surg., 56, 912.

Tuttle, S. G., and Grossman, M. I. (1958). Detection of gastro-esophageal reflux by simultaneous measurement of intraluminal pressure and $p \mathrm{H}$. Proc. Soc. exp. Biol. (N.Y.), 98, 225.

Ward, A. S., Wright, D. H., and Collis, J. L. (1970). The assessment of oesophagitis in hiatus hernia patients. Thorax, 25, 568.

Woodward, D. A. K. (1970). Response of the gullet to gastric reflux in patients with hiatus hernia and oesophagitis. Thorax, 25, 459. 